\title{
Evaluation of Tuberculosis Treatment Outcome of TB/HIV Co-Infection: A Four-Year Retrospective Cohort Study in HIV-Prevalent Setting of North Central Nigeria
}

\author{
Abiodun Hassan ${ }^{1}$, Richard Olukolade ${ }^{1}$, Queen Ogbuji ${ }^{1}$, Audu Onyemocho ${ }^{2}$, Lucia Okwuonye ${ }^{1}$, \\ Shember-agela Igbabul ${ }^{3}$, Josephine Okechukwu ${ }^{4}$, Oluremilekun Kusimo ${ }^{1}$, Adewale Osho', \\ Kehinde Osinowo', Oladapo Ladipo ${ }^{1}$ \\ ${ }^{1}$ Association for Reproductive and Family Health, Abuja, Nigeria \\ ${ }^{2}$ Department of Community Health, Benue state University, Makurdi, Nigeria \\ ${ }^{3}$ Benue state Tuberculosis and Leprosy Control Programme, Ministry of Health, Makurdi, Nigeria \\ ${ }^{4}$ FCT Tuberculosis and Leprosy Control Programme, FCT Health Management Board, FCT, Abuja, Nigeria \\ Email: stremi2001@yahoo.com
}

How to cite this paper: Hassan, A., Olukolade, R., Ogbuji, Q., Onyemocho, A., Okwuonye, L., Igbabul, S., Okechukwu, J., Kusimo, O., Osho, A., Osinowo, K. and Ladipo, O. (2016) Evaluation of Tuberculosis Treatment Outcome of TB/HIV CoInfection: A Four-Year Retrospective Cohort Study in HIV-Prevalent Setting of North Central Nigeria. Journal of Tuberculosis Research, 4, 122-133.

http://dx.doi.org/10.4236/jtr.2016.43015

Received: May 23, 2016

Accepted: September 4, 2016

Published: September 7, 2016

Copyright $\odot 2016$ by authors and Scientific Research Publishing Inc. This work is licensed under the Creative Commons Attribution International License (CC BY 4.0).

http://creativecommons.org/licenses/by/4.0/ (c) (i) Open Access

\begin{abstract}
Background: Despite the availability of highly effective treatment for decades, Tuberculosis (TB) remains a major health problem in Nigeria due to the increasing association between HIV and TB observed over the past three decades when HIV was discovered. However, the proportion of TB and or TB/HIV co-infected patients who have successful TB treatment outcome is not well known. This study determined the treatment outcome of TB/HIV co-infected patients with HIV negative patients in two states in Nigeria. Materials and Methods: A retrospective study of secondary data from eight Directly Observed Treatment Short (DOTS) course and AntiRetroviral Therapy (ART) service providers in Benue and Federal Capital Territory (FCT), Nigeria, was carried out. The period under review covers January, 2010 to December, 2013. Results: Out of the total 5266 TB cases reviewed, the HIV prevalence rate was $52 \%$. They were predominantly (53.3\%) male with mean age of 34.4 years $(\mathrm{SD}=15.1$ years). More than two-third $(72.5 \%)$ of HIV-negative patients had successful treatment compared to 1718 (62.7\%) HIV-positive patients. Of the 2334 HIV co-infected patients, $19.5 \%$ defaulted, $11.5 \%$ had died, $5.6 \%$ were transferred out and $0.7 \%$ failed treatment compared to HIV-negative patients amongst whom $18.3 \%$ defaulted, $3.6 \%$ died, $3.9 \%$ were transferred out and $1.6 \%$ failed treatment $(\mathrm{p}<$ 0.05). TB/HIV co-infected patients with baseline CD4 of $\geq 300 \mathrm{cell} / \mathrm{mm}^{3}$ are more likely to have successful treatment outcome $\{\mathrm{OR}-1.541(95 \% \mathrm{CI}=1.030-2.305) \mathrm{p}=$ $0.035\}$. Patients $\geq 45$ years old and those not on Co-trimoxazole Preventive Therapy $(\mathrm{CPT})$ are more likely to have unsuccessful treatment outcome $\{\mathrm{OR}-1.022(95 \% \mathrm{CI}=$ $0.643-1.488) \mathrm{p}=0.918$ and $\mathrm{OR}-1.306(95 \% \mathrm{CI}=0.956-1.555)$ respectively.
\end{abstract}


Conclusion: The favourable treatment outcome of HIV-negative patients is more than that of HIV-positive patients and the most probable predictable factor responsible is the CD4 count of patient; indicating that TB/HIV co-infection has remained a major public health problem in Benue state and FCT. Hence there is the need for sustained strengthening and expansion of the national TB/HIV programmes.

\section{Keywords}

Tuberculosis, Treatment Outcomes, TB/HIV, Co-Infection, DOTS

\section{Introduction}

The increasing association between Human Immunodeficiency Virus (HIV) and Tuberculosis (TB) observed over the past three decades a significant challenge to TB control, especially in low income settings [1]. According to the Global TB Report 2014, the burden of TB is highest in Asia and Africa with the African region bearing 24\% of the world's TB burden and the highest rates of cases and deaths per capital. Of the estimated 8.6 million new cases of TB, 13\% were co-infected with HIV and 1.3 million people died from TB, including almost one million deaths among HIV-negative individuals and 320,000 among people who were HIV-positive [2]. Concomitant treatment of Tuberculosis and HIV is also faced with a number of challenges including a higher pill burden and overlapping drug toxicities which may also affect adherence to the drug regimen and treatment outcomes for TB. This is also of concern in the emergence of multi-drug resistant tuberculosis among these patients [2] [3].

It's already 20 years since Nigeria adopted the Directly Observed Treatment Short Course (DOTS) TB strategy (in 1994) and is now implementing the STOP TB strategy which has as some of its targets to reduce the TB prevalence and death rates by $50 \%$ relative to 1990 level and to eliminate by 2050, TB as a public health burden. The continued high incidence of TB has been attributed to HIV co-infection [4] [5]. The number of new smear positive TB cases notified increased from 8449 in 1994 to 100,401 all forms of TB cases in 2013 [6]. With an estimated population of about 174 million people and a TB prevalence rate of 326 per 100,000 population, Nigeria is ranked $10^{\text {th }}$ among the $22^{\text {nd }}$ high burden countries worldwide [6]. Nigeria has an estimated general population HIV sero-prevalence of 4.6\% [7]. The prevalence of HIV among TB patients increased from $2.2 \%$ in 1991 to $19.1 \%$ in 2001 and $25 \%$ in 2010 and recent decline to $22 \%$ in 2013 [6] [7]. In Benue state and FCT-Abuja, HIV prevalence declined from 12.2 to $5.6 \%$ and $8.6 \%$ to $7.5 \%$ from 2007 to 2012 respectively while up to $33.1 \%$ and $49 \%$ of patients with TB are co-infected with HIV in both states respectively [8]-[10].

The number of TB/HIV related unfavorable treatment outcomes has reduced worldwide due to increased access to anti-retroviral (ARV) therapy [1]. However, in Nigeria the proportion of TB in comparison with TB/HIV co-infected patients who have successful TB treatment outcome is not well known or ascertained [10] [11]. There is also paucity of data on how treatment outcomes among TB/HIV co-infected patients are 
influenced by TB/HIV collaborative activities in the country. Therefore, the main goal of this research is to determine the treatment outcome of all TB patients and comparing the treatment outcomes between co-infected TB/HIV and TB patients in two states with high HIV burden and high TB burden in Nigeria. The success or otherwise of the implementation of the TB/HIV control strategies will determine whether the second objective of the STOP TB strategy (Protect vulnerable populations from TB, TB/HIV and multidrug-resistant TB) as well as Goal-3 of the Sustainable Development Goal (SDG) which emphasized healthy lives and well-being for all; could be achieved.

\section{Materials and Methods}

\subsection{Study Design}

A retrospective cohort study of all available secondary data of $\mathrm{TB}$ and $\mathrm{TB} / \mathrm{HIV}$ co-infection cases registered annually by the Tuberculosis and Leprosy Control Programme (TBLCP) control programme of the Ministry of health of Benue state and FCT-Abuja; and the ART clinical records at the health facilities including HIV collaborative activities was employed for the survey. The period under review covers from January, 2010 to December, 2013.

The data collected for this study was resisted to the scope, which is the proportion of TB and TB/HIV co-infected patients who have successful TB treatment outcome after TB treatment. It was not intended to show case the relationship between HIV patients and other co-morbid conditions or diseases. For this purpose, only the TB/HIV data was collected during the data collection exercise.

\subsection{Description of Study Setting}

Benue state is located in the north central geographic zone of Nigeria. Benue State has an estimated population of 4,712,020 in 2010 (i.e. $2.8 \%$ projection from 2006 National population figures of 4,219,244). There are two main ethnic groups, Tiv and Idoma. Other ethnic groups include Igede, Etulo and Jukun. The Benue people are mostly farmers engaged in subsistence and commercial farming. A small percentage of the populations are involved in petty trading and civil service jobs. On the order hand, FCT-Abuja is the political capital and metropolitan city and is also located in the north central zone. With increasing influence of urbanization and growing widespread insurgencies in some parts of the country, there is continued influx of people into Abuja with an annual growth rate of $9.3 \%$. Benue state has an estimated population that is thrice as high as FCT; 4.22 million compare with 1.41 million in FCT [12]. Aside the cosmopolitan civil servant and private sector dwellers, the native dwellers in Abuja are the traditional Gwari people who are mainly farmers and petty traders. The TB DOTS programme in Benue, supported by Netherlands Leprosy Relief (NLR) started in 2001 as a pilot project in four LGAs; Gwer, Otukpo, Logo and Ohimini and later expanded to cover the 23 LGAs.

In FCT, the Tuberculosis control programme commenced in 2003 with support from USAID and other partners including The Leprosy Mission Nigeria and the World 
Health Organization (WHO). As at 2012, Benue State and FCT had achieved 100\% DOTS coverage in all the local government areas/area councils with 142 DOTS clinics and 45 Microscopy centers in Benue and 52 DOTS centers and 25 Microscopy canters in FCT respectively. The Centres are designated as either, secondary or tertiary facility, based on the type of services offered and they have both public and private ownership [6]. During the reviewed period, the national guidelines for ART for HIV/TB co-infection followed the 2006 World Health Organization Guidelines for ART. As per these guidelines, all HIV-infected persons with pulmonary TB, extra-pulmonary or disseminated $\mathrm{TB}$ with a CD4-lymphocyte count $\leq 350 / \mathrm{mm}^{3}$ were considered eligible for ART. The most common ART regimen initiated was Zidovudine or Stavudine plus Lamivudine plus Efavirenz.

\subsection{Eligibility Criteria/Sampling Technique}

All individual registered for treatments that are eligible for both ART and TB treatment services in any of the DOTS comprehensive sites were included for the study and persons whose test results were incomplete for HIV were excluded. Being a retrospective cohort study that made use of secondary data, unconfirmed and inaccurate recordings against patients' uptake of services in ART and TB service delivery points were not included in the sample. Only those with clear recordings were used.

In each states (Benue and FCT) where this study was conducted, four health facilities with highest TB burden providing ART comprehensive services were selected using outlier sampling methodology by first ranking the facilities with the highest notification data for Tuberculosis in the two states. These includes: General hospital Gboko, Federal Medical Centre Makurdi, Saint Vincent's hospital Alaide and General hospital Otukpo in Benue state; and University of Abuja Teaching hospitals, Maitama District General hospital, Asokoro District hospital and Saint Vincent hospital Kubwa in FCT-Abuja.

\subsection{Data Collection}

The main data source from each center where the routine NTBLCP standardized facility reporting and recording forms, and ART Patient Management Monitoring (PMM) registers. Information on the socio-demographic variables, type of TB patient, site of diagnosis, date of diagnosis, sputum smear results, HIV status, Co-trimoxazole presumptive therapy, ART regimen, $\mathrm{CD} 4$ count (baseline and the most recent), duration of TB treatment and treatment outcome were extracted from the records. Data collection was done manually. The TB, ART and pre-ART health facility registers and patient treatment cards were provided by the facility research participants and the information seen were exported to the extraction sheet. Where there was incomplete information, LGA TB registers, TB suspects registers, patients sputum follow up registers and ART clinic laboratory records register were used as supportive registers.

\subsection{Outcome Measurements}

The Nigerian NTLCP guideline (2), adopted from WHO, was used for the clinical case 
and treatment outcome definitions (6). These outcomes include:

1) Cured: TB patient who was smeared positive at diagnosis, who completed 6 or 8 months of treatment and who is smear negative at the end of $6^{\text {th }}$ or $7^{\text {th }}$ month of treatment and at least one previous occasion.

2) Treatment completed: TB patient who was smeared positive at diagnosis and who completed treatment but in whom smear examination results are not available at the end of treatment, or all smear negative and extra-pulmonary TB patients who completed treatment.

3) Successful Treatment: The sum of cured and treatment completed.

4) Failure: A smear positive patient who while on Category 1 treatment remained, or became smear positive again five months or later after commencement of treatment.

5) Defaulted: A patient who has been on treatment for at least four weeks and whose treatment was interrupted for eight or more consecutive weeks.

6) Transfer Out: A TB patient already registered for treatment in one LGA/State who is transferred to another State and whose treatment is not known.

7) Died: TB patient who dies for any reason during the course of anti-tuberculosis chemotherapy.

It is worth mentioning that the regimen for the treatment of drug susceptible TB is for a period of six months and the treatment outcomes are given at the completion of the treatment regimen. TB Patients at the commencement of treatment are subjected to follow-up microscopy tests after diagnosis at month two [2], month five [5] and month six [6] during the period of treatment to confirm that there is a conversion of the TB patient status during that period. These laboratory tests are aimed to confirm whether or not a patient has been cured of the disease. Irrespective of the result of the outcomes of the microscopy tests, a TB patient cannot be declared cured or otherwise, until all the follow-up tests have been conducted till the end of treatment. On the other hand, for TB patients with smear negative result at diagnosis but who were confirmed to be symptomatic to TB by a medical officer, treatment outcome is also given at the end of the completion of the treatment regimen.

\subsection{Data Analysis}

Data was extracted, checked for errors and entered into Statistical Packages for Social Sciences (SPSS) version 20.0 for analysis. Descriptive statistics were used to summarize the independent variables of interest and chi square $\left(\chi^{2}\right)$ test was used for test of association between the independent variables and the main outcome of the study, with statistical significance set at $\mathrm{p}$-value of $5 \%$. Multivariate analysis was done to analyze whether there is association between the TB treatment outcomes and independent predictors that have significant chi-square. Crude and adjusted odd ratio were computed and used to see the strength of association. Cut off values for independent variables in the multivariate analysis was 0.05 .

\subsection{Ethical Approval}

Ethical approval for the surveys was obtained from the National Health Research Ethics 
committee, Benue State ministry of health and the department of public health, FCT-Abuja. Approval from the management of the selected health facilities were also sought for.

\section{Results}

\subsection{Socio-Demographic Characteristics and HIV Status}

Of the 5266 patients registered in the all facilities surveyed, more than half $(52.0 \%)$ were TB/HIV co-infected, $44.3 \%$ were sero-negative for HIV and $3.6 \%$ of the patients HIV status was not known. The patients were between 3 months to 95 years of age. The modal age group was 30 - 44 years (41.0\%), followed by 15 - 29 years (29.3\%) while 90 years and above constituted the least $(0.1 \%)$. The mean age of the patients was 34.7 years ( $S D=15.1$ years). Overall, the proportions of male seen in all the facilities annually were higher than the females (53.3\% and $46.7 \%$ respectively) with a male: female ratio of 1.14. 1503 (54.9\%) females and 1237 (45.1\%) males were co-infected with HIV $(\mathrm{p}=0.000)$; male: female ratio was 0.82 . Majority of the co-infected are between $30-44$ years old $(\mathrm{p}=0.000)$. Mean age $=34.7$ years $(\mathrm{SD}=15.1$ years $)($ Table 1$)$.

\subsection{Treatment Outcome}

1693 (72.5\%) HIV-negative patients had successful treatment compared to 1718 (62.7\%) HIV-negative patients and 103 (53.6\%) HIV-unknown patients $(P=0.000)$. The cure rate among the HIV-negative patients was $826(62.0 \%)$ as against 483 (36.2\%) HIV positive patients and $24(1.8 \%)$ HIV-unknown patients $(\mathrm{p}=0.000)$. The overall mean treatment success rate was $66.7 \%$, of which $25.3 \%$ were cured of TB and $41.4 \%$ completed their treatment. 535 (19.5\%) and 427 (18.3\%) HIV-positive and HIV-negative patients respectively defaulted treatment. 315 (11.5\%) HIV-patients and 85 (3.6\%) HIV-negative patients died during the course of treatment, while 19 (0.7\%) HIV-patients and 38 (1.6\%) HIV-negative patients were recorded as treatment failure.

Table 1. Age and sex distribution of TB patients by HIV status, 2010-2013.

\begin{tabular}{|c|c|c|c|c|c|}
\hline Characteristics & & HIV Status & & & \\
\hline \multicolumn{6}{|r|}{$\begin{array}{c}\text { Statistical } \\
\text { Significance }\end{array}$} \\
\hline Sex & & & & & \\
\hline Male & $1237(45.1)$ & $1465(62,8)$ & $105(54.7)$ & $2,807(53.3)$ & $\mathrm{p}$-value $=0.000$ \\
\hline Female & $1503(54.9)$ & $869(37.2)$ & $87(45.3)$ & 2,459 (46.7) & \\
\hline Total & $2740(100 \%)$ & $2334(100 \%)$ & $(192(100 \%)$ & $5266(100 \%)$ & \\
\hline \multicolumn{6}{|l|}{ Age Group } \\
\hline $0-14$ & $219(8.0)$ & $129(5.5)$ & $21(10.9)$ & $369(7.0)$ & $\mathrm{p}$-value $=0.000$ \\
\hline $15-29$ & $681(24.9)$ & $816(35.0)$ & $47(24.5)$ & $1544(29.3)$ & \\
\hline $30-44$ & $1352(49.3)$ & $735(31.5)$ & $73(38.0)$ & $2160(41.0)$ & \\
\hline $45-59$ & $400(14.6)$ & $358(15.3)$ & $28(14.6)$ & $786(14.9)$ & \\
\hline $60-74$ & $77(2.8)$ & $236(10.1)$ & $16(8.3)$ & $329(6.2)$ & \\
\hline $75-89$ & $10(0.4)$ & $56(2.4)$ & $7(3.6)$ & $73(1.4)$ & \\
\hline $90+$ & $1(0.0)$ & $4(0.2)$ & $0(0.0)$ & $5(0.1)$ & \\
\hline Total & $2740(100 \%)$ & $2334(100.0)$ & $192(100.0)$ & $5266(100.0)$ & \\
\hline
\end{tabular}


The proportion of transferred out patients was higher amongst the HIV-positive patients $(5.6 \%)$ as compared to HIV-negative $(3.9 \%)(\mathrm{p}=0.000)$ (Figure 1).

Table 2 presents comparison of the distribution of TB treatment outcome and the HIV status by states of the patients. The treatment success rate among HIV negative in Benue state was $73.2 \%$ as against $71.9 \%$ HIV-negative patients in FCT-Abuja. Among the HIV positive patients, the success rate in Benue was also higher $(67.2 \%$ and $58.0 \%$ respectively). More deaths were recorded in FCT-Abuja (8.9\%), as compared to Benue state (7.1\%), and majority of the deaths in Benue occurred among the HIV-positive patients (9.5\%). Failure rate among HIV-negative patients in Benue State and FCT-Abuja was relatively higher (1.9\% and $1.3 \%)$ than the failure rate among HIV-positive patients ( $0.6 \%$ and $0.8 \%$ respectively).

\subsection{Predictors of Treatment Outcome}

Majority of patients below 44 years and those who had treatment supporter had more successful treatment outcome compared to the patients above 44 years and those without Treatment Supporter. However, while the relationship between the age and treatment outcome was statistically significant $(\mathrm{p}=0.004)$, that of the treatment supporter with treatment outcome was not statistically significant $(\mathrm{p}=0.060)$. The difference in treatment outcome between the TB/HIV co-infected patients with baseline CD4 count of $\geq 350$ cells $/ \mathrm{mm}^{3}$ and those with CD4 count of $\leq 349$ cells $/ \mathrm{mm}^{3}$ was statistically significant $(\mathrm{p}=0.024)$. Similarly, TB/HIV co-infected patients who were on cotrimoxazole prophylaxis therapy $(\mathrm{CPT})$ had successful treatment outcome more than those not on CPT $(\mathrm{p}=0.044)($ Table 3$)$.

\subsection{Multiple Logistic Regressions}

In risk analysis conducted for selected variables that have significant chi-square values, the TB/HIV co-infected patients with $\mathrm{CD} 4$ of $\geq 350 \mathrm{cell} / \mathrm{mm}^{3}$ are more likely to have

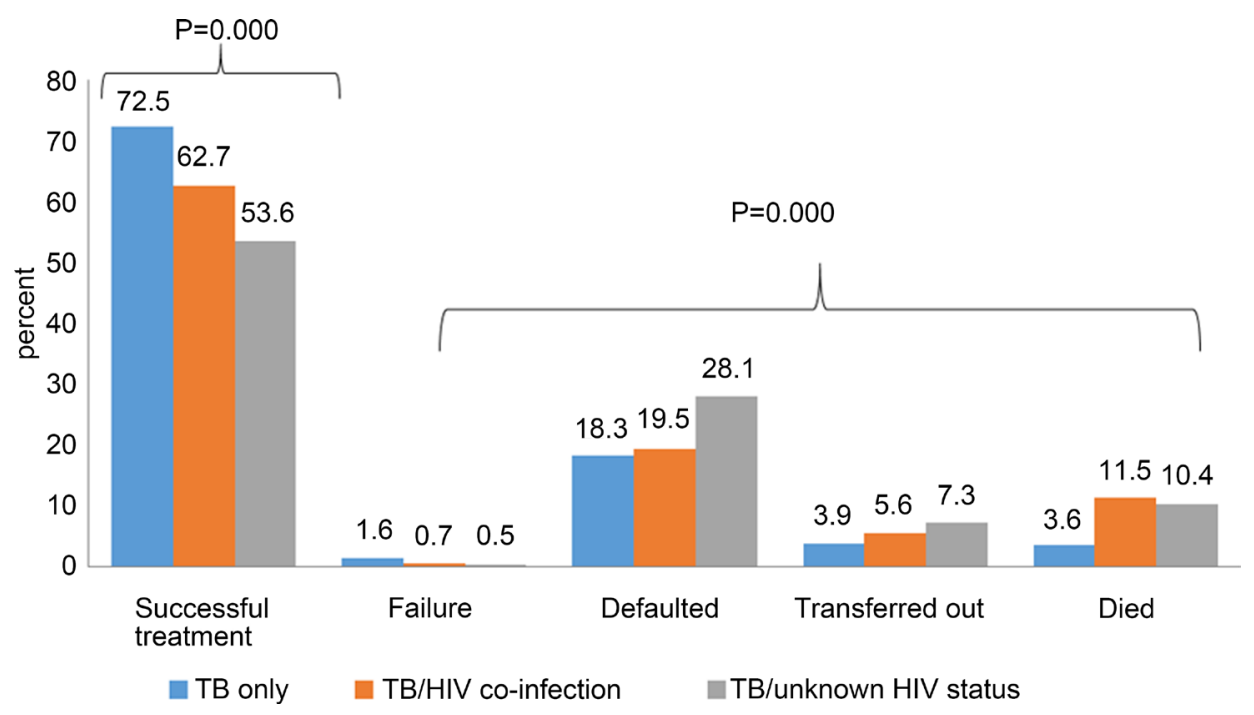

Figure 1. Percentage treatment outcome of TB patients by HIV status. 
Table 2. Treatment outcomes of TB patients and HIV status by State.

\begin{tabular}{|c|c|c|c|c|c|c|c|}
\hline \multirow[t]{2}{*}{ HIV Status } & \multicolumn{5}{|c|}{ Treatment Outcomes } & \multirow[b]{2}{*}{ Total } & \multirow[b]{2}{*}{$\begin{array}{c}\text { Statistical } \\
\text { Significance }\end{array}$} \\
\hline & $\begin{array}{l}\text { Successful } \\
\text { treatment }\end{array}$ & Failure & Defaulted & Transferred out & Died & & \\
\hline \multicolumn{8}{|l|}{ Benue State } \\
\hline Positive & $942(67.2)$ & $8(0.6)$ & $294(21.0)$ & $24(1.7)$ & $133(9.5)$ & 1401 & $\mathrm{p}$-value $=0.000$ \\
\hline Negative & $832(73.2)$ & $22(1.9)$ & $227(20.0)$ & $9(0.8)$ & $47(4.1)$ & 1137 & \\
\hline Not Done & $52(52.5)$ & $1(1.0)$ & $37(37.4)$ & $3(3.0)$ & $6(6.1)$ & 99 & \\
\hline \multicolumn{8}{|l|}{ FCT-Abuja } \\
\hline Positive & $776(58.0)$ & $11(0.8)$ & $241(18.0)$ & $129(9.6)$ & $182(13.6)$ & 1339 & $\mathrm{p}$-value $=0.000$ \\
\hline Negative & $861(71.9)$ & $16(1.3)$ & $200(16.7)$ & $82(6.9)$ & $38(3.2)$ & 1197 & \\
\hline Not Done & $51(54.8)$ & $0(0.0)$ & $17(18.3)$ & $11(11.8)$ & $14(15.1)$ & 93 & \\
\hline
\end{tabular}

Table 3. Percentage distribution of TB patients Characteristics by treatment outcome.

\begin{tabular}{|c|c|c|c|c|}
\hline \multirow[t]{2}{*}{ Characteristics } & \multicolumn{3}{|c|}{ HIV Status } & \multirow{2}{*}{$\begin{array}{c}\text { Statistical } \\
\text { Significance }\end{array}$} \\
\hline & Successfully treated & Not Successfully treated & Total & \\
\hline \multirow{2}{*}{\multicolumn{5}{|c|}{ Negative/Not Done }} \\
\hline & & & & \\
\hline$\geq 45$ & $758(63.5)$ & $435(36.5)$ & 1193 & \\
\hline \multicolumn{5}{|l|}{ Sex } \\
\hline Male & $1871(66.7)$ & $936(33.3)$ & 2807 & $\mathrm{p}$-value $=0.902$ \\
\hline Female & $1643(66.8)$ & $816(33.2)$ & 2459 & \\
\hline Disease site & $3401(67.0)$ & $1678(33.0)$ & 5079 & $\mathrm{p}$-value $=0.039$ \\
\hline Yes & $2118(65.8)$ & $1103(34.2)$ & 3221 & $\mathrm{p}$-value $=0.060$ \\
\hline No & $1396(68.3)$ & $649(31.7)$ & 2045 & \\
\hline \multicolumn{5}{|l|}{ Treatment category } \\
\hline New & $3271(66.7)$ & $1631(33.3)$ & 4902 & $\mathrm{p}$-value $=0.520$ \\
\hline Retreatment & $243(66.8)$ & $121(33.2)$ & 364 & \\
\hline \multicolumn{5}{|l|}{ Baseline CD4 count } \\
\hline$\leq 349$ & $510(72.6)$ & $192(27.4)$ & 702 & $\mathrm{p}$-value $=0.024$ \\
\hline$\geq 350$ & $145(80.1)$ & $36(19.9)$ & 181 & \\
\hline
\end{tabular}


successful treatment outcome $\{$ AOR-1.541 $(95 \% \mathrm{CI}=1.030-2.305) \mathrm{p}=0.035\}$. Patients $\geq 45$ years old and those not on CPT are more likely to have unsuccessful treatment outcome AAOR-1.022 (95\% CI $=0.643-1.488) \mathrm{p}=0.918$ and AOR-1.306 (95\% CI = $0.956-1.555$ respectively). HIV status of the patients on its own does not accounts for poor treatment success rate $(\mathrm{F} 1,5264=5.170, \mathrm{p}>0.005)$.

\section{Discussion}

This survey revealed that more than half of the TB patients were co-infected with HIV; a rate far above the estimated global figure of 13\% [2], and the co-infected patients have poor treatment outcome than the HIV-negative patients. This is slightly higher, than an earlier report in which $49 \%$ of patients with TB in FCT-Abuja had HIV co-infection [9] and a neighboring boundary like Nassarawa state where $41.2 \%$ was reported [11]. The finding is far higher than the prevalence rate of $23.2 \%$ reported for a hospital based study conducted in the south west of Nigeria [13] and 38.4\% reported for northwestern Nigeria [14]. The finding is consistent with reports from other Sub-Saharan Africa including Ethiopia (56\%) and Tanzania (43\%) [15] [16]. The high HIV-seroprevalence documented is the present study may be attributed to the high prevalence of HIV reported in the selected states; above the national average of 4.1\% [17]. The selection criteria could also be responsible, as the selected facilities for this study serve as the major free HIV referral Centres in Benue State and FCT-Abuja. The higher seroprevalence rate may therefore suggest good collaboration of TB and HIV activities in the Benue state and FCT since in the algorithm patients with presumptive TB are also subjected to HIV counseling and testing (HCT) when they presented in the facilities and vice-versa.

The treatment success of rate of $72.5 \%$ for HIV-negative patients and $62.7 \%$ for HIV-negative patients in this study is far short of the national target of $85 \%$ [2] and targets in other Sub-Saharan Africa like Ethiopia (80\%) [18].The gaps in the treatment success rate in this study compared to the national target may therefore suggest fair performance by Benue state and FCT-Abuja, TB programme. This is most likely due to the high rate of default in this study which may imply a reduction in patient's compliance within the period reviewed (Figure 1).

The low success rate in this study has public health implication unless steps are taken to address the gaps. In the advent of concurrent HIV infection, if the outcomes in our patients are not improved, achieving the MDGs goal 6 will be a mirage as development of Multi-Drug Resistant (MDR) TB may further jeopardized the efficacy of the available standardized tuberculosis chemotherapy thereby worsening the outlook for better tuberculosis control in Nigeria. The emergence of MDR-TB will pose serious challenge to the control of TB worldwide. Therefore, the disparity between the state TB treatment success rate and the national target should be explored by the state TB programme and the national TB programme as to improve the disease control. On the other hand, the disparity in the success rate between HIV-negative and HIV-positive patients may suggest inadequate laboratory support, as those with CD4 count of $\geq 350$ cells $/ \mathrm{mm}^{3}$ tend to have a better treatment outcome compared to those with CD4 of $\leq 350$ cells $/ \mathrm{mm}^{3}$ $\{$ OR-1.541 (95\% CI $=1.030-2.305\}$ (Table 4). In accordance with the national guideline 
Table 4. Multiple Logistic Regressions of predictors resulting to unsuccessful treatment outcome.

\begin{tabular}{cccc}
\hline Characteristics & \multicolumn{2}{c}{ Predicting factor } \\
\hline Age (years) & Adjusted Odds Ratio & 95\% Confidence Interval & p-value \\
\cline { 2 - 4 }$\leq 44$ & 1.022 & $0.643-1.488$ & \\
$\geq 45$ & Reference & & \\
CD4 count (cells $\left./ \mathrm{mm}^{3}\right)$ & & & \\
$0-14$ & & & 0.918 \\
$\leq 349$ & 1.541 & & \\
$\geq 350$ & Reference & & \\
CPT & & & $0.030-2.305$ \\
Yes & 1.306 & $0.956-1.555$ & \\
No & Reference & & \\
\hline
\end{tabular}

for ART and HIV/TB co-infection management adopted from the 2006 World Health Organization Guidelines for ART, all HIV-infected persons with pulmonary TB, extrapulmonary or disseminated TB with a CD4-lymphocyte count $\leq 350 / \mathrm{mm}^{3}$ were considered eligible for ART [6]. In this regard the 142 DOTS and 45 Microscopy centers in Benue and 52 DOTS centers and 25 Microscopy canters in FCT should be well equipped and properly funded for appropriate laboratory investigations required for the management of TB/HIV co-infection.

In this study, it was observed that the death rate amongst the HIV-positive patients was relatively higher as compared to the HIV-negative patients and it was statistically significant. The gap of $7.9 \%$ between the mortality rate of HIV-positive and HIV-negative patients is unacceptably high. Since TB is curable and advanced HIV/AIDS condition can be prevented by early diagnosis and treatment, prompt commencement of treatment and strict adherence to treatment regimen should be advocated. The high mortality rate among those whom the HIV status was not known may be due to negligence or lack of adequate health promotive measures.

\section{Conclusion}

This study has demonstrated a favourable treatment outcome in HIV-negative patients compared to HIV-positive patients in Benue and FCT-Abuja fort the four years period reviewed; indicating that $\mathrm{TB} / \mathrm{HIV}$ co-infection has remained a major public health problem in Benue state and FCT. Therefore, TB/HIV co-infection in Nigeria should be jointly managed and collaboration between the two programs needs to be strengthened and the services should be coordinated. In the nearest future, other authors could build on the findings of this paper using more recent and primary data as a follow-up study, to confirm the findings of this paper and to indicate possible variations which this study could not present owing to the limitation and use of secondary data.

\section{Acknowledgements}

We would like to extend our thanks to The Global Fund for technical assistance during the development of the study design/protocol and financial support. We would also like 
to acknowledge the Benue state Ministry of Health and FCT Health Management Board for their immense contribution and support through the protocol development and survey implementation. Our sincere thanks goes to the study participants, the hospital medical directors and staff as well as the data collectors.

\section{Authors' Contributions}

Hassan, Olukolade and Ogbuji designed the study and coordinated the survey and participated in manuscript development. Hassan, Olukolade, Igbabul, Onyemocho and Okechukwu jointly developed the data collection tools, collected data, analysis and drafted the manuscript. Hassan, Onyemocho, Osho, Ogbuji, Okwuonye, Olukolade and Osinowo participated in manuscript development and editing. All authors read, critically revised and approved the final manuscript. Ladipo is the guarantor and internal reviewer of the paper. Kusimo participated in Manuscript development and editorials.

\section{Funding}

This work was supported by The Global Fund to fight AIDS, Tuberculosis and Malaria [NGA-H-ARFH].

\section{References}

[1] World Health Organization (2012) Global Report for Research on Infectious Diseases of Poverty. www.who.int

[2] WHO (2013) Global Tuberculosis Report, 2013. WHO, Geneva. www.who.int/tb/data

[3] Mekdes, K.G., Gunnar, A.B. and Jan, C.F. (2010) Barriers and Facilitators of Adherence to TB Treatment in Patients on Concomitant TB and HIV Treatment: A Qualitative Study. BMC Public Health, 10, 651.

[4] WHO encyclopedia.com. Worldmark Encyclopedia of Nations, 2007. www.who.int/tb/data

[5] WHO Report 2008. Global Tuberculosis Control: Surveillance, Planning, Financing. www.who.int

[6] Global Tuberculosis Report 2014. www.who.int

[7] United State Embassy in Nigeria (2014) Nigeria Tuberculosis Fact Sheet 2012. http://nigeria.usembassy.gov

[8] Lawson, L., Yassin, M.A., Thacher, T.D., Olatunji, O.O., Lawson, J.O., Akingbogun, T.I., et al. (2008) Clinical Presentation of Adults with Pulmonary Tuberculosis with and without HIV Infection in Nigeria. Scandinavian Journal of Infectious Diseases, 40, 30-35. http://dx.doi.org/10.1080/00365540701509899

[9] Jamda, M.A., Lawson, L., Nnodu, O.O., Ajani, M.N., Umobong, E.O., Fredrick, C.C., et al. (2014) Treatment Outcome of Patients Co-Infected with Tuberculosis and HIV in Abuja, Nigeria. Nigerian Journal of Basic and Clinical Sciences, 11, 72-75.

[10] Jemikalajah, J.D. and Okogun, G.A. (2008) Health Point Prevalence of Human Immunodeficiency Virus and Pulmonary Tuberculosis among Patients in Various Parts of Delta State, Nigeria. Saudi Medical Journal, 30, 387-391.

[11] Pennap, G., Makpa, S. and Ogbu, S. (2010) Sero-Prevalence of HIV Infection among Tuberculosis Patients in a Rural Tuberculosis Referral Clinic in Northern Nigeria. The Pan African Medical Journal, 5, 22. 
[12] National Population Commission, Nigeria Facts and Figures 2006 Census. http://www.population.gov.ng

[13] Ige, O.M. and Oladokun, R.E. (2011) Treatment Outcome of Newly Diagnosed Sputum Positive Adult Tuberculosis Cases in the Context of HIV Infection. Journal of Infectious Disease and Immunity, 3, 210-217.

[14] Dauda, M. (2010) Evaluation of the Efficacy of Directly Observed Treatment Short Course (DOTS) in Patients with Tuberculosis and HIV Infection in Kano, Nigeria. RIF, 1, 218-223.

[15] Range, N., Ipuge, Y.A., O’Brien, R.J., Egwagab, S.M., Mfinanga, S.G., Chonde, T.M., et al. (2001) Trend in HIV Prevalence among Tuberculosis Patients in Tanzania, 1991-1998. The International Journal of Tuberculosis and Lung Disease, 5, 405-412.

[16] Bruchfeld, J., Aderaye, G., Palme, I.B. and Bjorvatn, B. (2002) Evaluation of Outpatients with Suspected Pulmonary Tuberculosis in a High HIV Prevalence Setting in Ethiopia: Clinical, Diagnostic and Epidemiological Characteristics. Scandinavian Journal of Infectious Diseases, 34, 331-337. http://dx.doi.org/10.1080/00365540110080025

[17] Federal Ministry of Health [Nigeria] (2013) National HIV \& AIDS and Reproductive Health Survey, 2012 (NARHS Plus). Federal Ministry of Health Abuja, Nigeria.

[18] Yassin, M.A., Datiko, D.G. and Shargie, E.B. (2006) Ten Year Experiences of Tuberculosis Control Programme in the Southern Region of Ethiopia. The International Journal of Tuberculosis and Lung Disease, 10, 1166-1171.

Submit or recommend next manuscript to SCIRP and we will provide best service for you:

Accepting pre-submission inquiries through Email, Facebook, LinkedIn, Twitter, etc.

A wide selection of journals (inclusive of 9 subjects, more than 200 journals)

Providing 24-hour high-quality service

User-friendly online submission system

Fair and swift peer-review system

Efficient typesetting and proofreading procedure

Display of the result of downloads and visits, as well as the number of cited articles

Maximum dissemination of your research work

Submit your manuscript at: http://papersubmission.scirp.org/ 